\title{
The activity budgets and activity patterns of sympatric grey rhebok and mountain reedbuck in a highveld grassland area of South Africa
}

\author{
- W. A. Taylor ${ }^{1} *$, \\ - J. D. Skinner ${ }^{1}$ and \\ - R. C. Krecek ${ }^{2,3}$
}

\author{
${ }^{1}$ Veterinary Wildlife Unit, Faculty of Veterinary Science, University of Pretoria, Private \\ Bag X04, Onderstepoort 0110, South Africa, \\ ${ }^{2}$ Ross University School of Veterinary Medicine, PO Box 334, Basseterre, St Kitts, West \\ Indies and \\ ${ }^{3}$ Department of Zoology, Auckland Park Campus, University of Johannesburg, PO Box \\ 524, Auckland Park 2006, South Africa
}

[Figures at the bottom of the document]

\begin{abstract}
Behavioural observations were carried out on grey rhebok and mountain reedbuck at Sterkfontein Dam Nature Reserve, South Africa, for a period of 1 year between May 2001 and April 2002. Four harem herds of grey rhebok, five territorial male mountain reedbuck and female mountain reedbuck (herds grouped as one individual) were monitored to determine activity budgets and activity patterns. Both species spent more time feeding in the late afternoon during relatively cool temperatures, and more time resting in the middle of the day during relatively high temperatures. Statistical comparisons between the two species of the percentage time feeding and resting found no differences between them, although mountain reedbuck spent more time resting overall than grey rhebok. Both species were active at night.
\end{abstract}




\section{Resumé}

Des observations du comportement du rhebuck gris et du redunca de montagne ont été réalisées dans la Sterkfontein Dam Nature Reserve, en Afrique du Sud, pendant une période d'un an, de mai 2001 à avril 2002. On a suivi quatre harems de rhebucks, cinq reduncas mâles territoriaux et des femelles reduncas (les hardes étant considérées comme un seul individu) pour déterminer le budget des activités et leurs schémas. Les deux espèces passent plus de temps à se nourrir en fin d'après-midi quand la température est plus fraîche, et plus de temps à se reposer à la mi-journée, quand la température est relativement haute. Des comparaisons statistiques du temps passéà se nourrir et à se reposer ne montrent pas de différences entre les deux espèces, même si le redunca de montagne passait en général plus de temps à se reposer que le rhebuck. Les deux espèces étaient actives pendant la nuit.

\section{Introduction}

Grey rhebok Pelea capreolus (Forster, 1790) and southern mountain reedbuck Redunca fulvorufula fulvorufula (Afzelius, 1815) are antelope species of similar size and appearance that are often sympatric in South Africa. Molecular phylogeny places them in the same subfamily, Reduncinae, a small taxon that includes the common reedbuck (Redunca redunca) and species in the genus Kobus (Matthee \& Davis, 2001). Both use rocky hillsides and steep mountain grasslands that form marginal habitat for other ungulate species (Rowe-Rowe, 1983, 1994).

They differ, however, in two important aspects of ecology: feeding behaviour and social structure. Grey rhebok feed selectively on forbs (Ferreira \& Bigalke, 1987; Beukes, 1988), and form small, stable harem herds comprising one adult male, two to five females and accompanying young (Esser, 1973; Ferreira, 1983). The mating system is female defence polygyny, with females staying with the same harem male permanently. These males are strongly territorial (Taylor, 2004), while males without harems remain solitary.

Mountain reedbuck are selective grazers (Irby, 1976) and have a mating system of resource defence polygyny (Irby, 1979). Their social organization consists of territorial males, small unstable female herds with young (three to eight adults), and non-territorial bachelor groups (Irby, 1976). Territorial males occupy their territories all year, while females move from one male's territory to another (Irby, 1976; Dunbar \& Roberts, 1992). 
As a result of these ecological differences, the two species were expected to show behavioural adaptations that reflect their different requirements. The aim of the present study was to investigate these adaptations by quantifying activity budgets and patterns, and compare any diurnal and seasonal variation between the two species.

\section{Materials and Methods}

\section{Study site and animals}

The present study was conducted at Sterkfontein Dam Nature Reserve (hereafter Sterkfontein) $\left(28^{\circ} 24^{\prime} \mathrm{S}, 2^{\circ} 02^{\prime} \mathrm{E}\right)$, situated in the Free State Province of South Africa. Sterkfontein has a mild climate with an average annual temperature of $17^{\circ} \mathrm{C}$ and summer rainfall averaging $680 \mathrm{~mm}$. It is located within the moist cool highveld grassland (Bredenkamp \& van Rooyen, 1996). The study site, which was enclosed by a 2.4-m game fence on three sides and by the dam on the fourth side, comprised a small section of the Reserve, with an area of 550 ha and altitudes of 1700-1900 m.

Observations were made on four harem herds of grey rhebok and, within each herd, three social categories were differentiated. These were: (i) territorial harem males; (ii) adult and sub-adult females ( $>1$ year) and; (iii) all lambs under 5 months of age. Juvenile males and females were excluded ( $>5$ months). Females and sub-adult females within the same herd were treated as one 'individual', with their data being pooled and averaged. Lambs under 5 months of age from the same herd were also treated as one individual. Their ages were known because they were born during the study period.

In mountain reedbuck, observations were made on five territorial males, and their behaviour was differentiated from that of adult and sub-adult females. Female herds were observed in four separate areas but, because of their unstable nature and large home ranges of individuals, there was overlap of females and areas. As a result, all observations were pooled as one average 'individual' female. Behaviour of juveniles ( $<1$ year) and lambs was excluded.

\section{Behavioural observations}

Behaviour was measured predominantly by scan observations (Martin \& Bateson, 1993), whereby a group of subjects were rapidly scanned once every $2 \mathrm{~min}$, and the behaviour of each animal recorded at that instant. Observations were carried out either from a vehicle, or on foot from a hidden position, and animals were watched with binoculars from 
distances varying between 50 and $300 \mathrm{~m}$. If the animals were disturbed, behavioural recording was delayed until they appeared to ignore the observer.

Observation periods lasted between 1 and $3 \mathrm{~h}$, unless the subjects moved out of sight or were disturbed. These were carried out between 06.00 and 18.00 hours between May 2001 and April 2002, and at varying times of the day to represent all periods. In total, 295 1-h observation periods were conducted on grey rhebok herds, 247 of which included harem males. For mountain reedbuck, 141 1-h observation periods were conducted on males and 109 on female herds. For purposes of estimating activity budgets and patterns, observation periods longer than $1 \mathrm{~h}$ were split into separate hourly segments. To ensure that all animals and all time periods were equally represented, an average was calculated for each individual in each time period, and these values were used to estimate an overall average for each species.

During observations at distances $<100 \mathrm{~m}$, behaviour was split into the following categories: feeding, standing head up, standing grooming, walking/running, defecating/urinating, ruminating, drinking, lying inactive, lying grooming, and sexual behaviour. When observations took place at distances $>100 \mathrm{~m}$, ruminating behaviour was not recorded; any ruminating behaviour that occurred was then included as lying inactive or standing head up.

Nocturnal behaviour was recorded in grey rhebok on eight occasions (five times in summer, three in winter) and in mountain reedbuck on four occasions (twice in summer, twice in winter), with observation periods lasting $6 \mathrm{~h}$. Due to the difficulties of viewing at night, behavioural categories were restricted to active (incorporating standing, walking and feeding) or inactive (lying).

\section{Results}

\section{Diurnal activity budgets}

Diurnal activity budgets were estimated in grey rhebok males, females and lambs (Fig. 1), and male and female mountain reedbuck (Fig. 2). These represent the overall averages of percentage time spent performing various behavioural activities during the day. 


\section{Diurnal activity patterns}

The percentages of times spent in different activities (separated into inactivity, feeding, and other active behaviour), during different periods of the day (split into four periods of 3-h intervals), for adult grey rhebok and mountain reedbuck are shown in Fig. 3. In grey rhebok, the timing of activities of males and females overlapped, so they were active or inactive at the same time. This was not necessarily the case for mountain reedbuck because males and females often rested at different times.

In grey rhebok, variation in percentage time feeding was tested using a three-way ANOVA comparing different animals (three males, three females), seasons (summer versus winter), and times of day. In the latter, time was split into four periods, comprising 06.00-08.59, 09.00-11.59, 12.00-14.59 and 15.00-17.59 hours. The test was balanced and used eight independent data points per animal, per season, and per time of day. Data were arcsine transformed. Significant differences were found between animals ( $F=2.776$, d.f. $=5, P=0.018)$, between seasons $(F=8.416$, d.f. $=1, P=0.004)$, and between times of day $(F=9.841$, d.f. $=3, P<0.001)$. There were no interactions. Multiple pairwise comparisons using the Tukey test indicated that grey rhebok spent more time feeding in winter than in summer, and more time feeding during the time period 15.00-17.59 hours than at all other times of day. The Tukey test did not indicate which animals differed from each other.

To investigate variation in percentage time resting in grey rhebok, another three-way ANOVA (balanced design) was used, comparing animals, seasons, and times of the day as above. Data were arcsine transformed. A significant difference was found between animals $(F=3.986$, d.f. $=5, P=0.002)$ and between times of day $(F=12.683$, d.f. $=3$, $P<0.001)$. There were no differences between seasons $(F=1.177$, d.f. $=1, P=0.279)$ and no interactions. Multiple pairwise comparisons using the Tukey test indicated that grey rhebok rested more during the middle of the day (09.00-14.59 hours) than in the early morning (06.00-8.59 hours) and late afternoon (15.00-17.59 hours). Group 4 females differed from the male from group 2 .

In territorial male mountain reedbuck, variation in percentage time feeding was tested using a two-way ANOVA comparing different males $(\mathrm{n}=5)$ and times of day (as for grey rhebok). Seasonal differences were not tested due to insufficient winter data. The test was balanced and used six independent data points per male and per time of day. There were no differences between males $(F=0.216$, d.f. $=4, P=0.929)$ but there was evidence of a difference between times of day $(F=5.492$, d.f. $=3, P=0.002)$. There was no interaction ( $F=0.98$, d.f. $=12, P=0.473$ ). Multiple pairwise comparisons using the Tukey test 
indicated that they spent more time feeding during the period 15.00-17.59 hours than during the period 12.00-14.59 hours.

Variation in percentage time resting was also tested using a two-way ANOVA (balanced design) comparing different males $(\mathrm{n}=5)$ and times of day. There were no differences between males ( $F=0.111$, d.f. $=4, P=0.978$ ), but there was evidence of a difference between times of day $(F=8.090$, d.f. $=3, P<0.001)$. There was no interaction $(F=0.775$, d.f. $=12, P=0.674)$. Multiple pairwise comparisons using the Tukey test indicated that they spent less time resting during the period 15.00-17.59 hours than at any other time of day.

The percentage time spent feeding and resting was then compared between the two species using two one-way ANOVA. Six grey rhebok (three males, three females) and five mountain reedbuck males were included. The analyses were confined to summer data collected during the time periods $09.00-11.59$ and $12.00-14.59$ hours, and comprised sixteen data points for each grey rhebok, and 12 data points for each mountain reedbuck. There were no differences in the time spent feeding between the two species ( $F=0.186$, d.f. $=10, P=0.997)$ and no differences in the time spent resting $(F=1.41$, d.f. $=10, P=0.181)$.

\section{Patterns of activity and inactivity}

A typical day for grey rhebok involved foraging for between 1 and $2 \mathrm{~h}$, followed by a rest period of similar length. This was then followed by more activity for $1-2 \mathrm{~h}$, and then more resting. Although they were generally less active during the middle of the day than at other times, hot conditions did not always stop them from feeding. Mountain reedbuck activity periods were generally more fixed, with midday normally being a period of inactivity, especially in hot weather.

\section{Nocturnal activity patterns}

At night, grey rhebok were active for $57 \%$ of the time, while mountain reedbuck were active for $72 \%$ of the time. Both species were active on and off throughout the night during both summer and winter.

\section{Ruminating}

Due to the difficulties in observing ruminating behaviour, the number of observation periods in which it was quantified was small and unevenly spread between times of day. No statistical analysis was performed. During periods of lying down, grey rhebok spent an average of $33 \%$ of the time ruminating; giving an overall time spent ruminating of 
$14 \%$. Mountain reedbuck ruminated for $40 \%$ of the time while lying down; giving an overall time spent ruminating of $22 \%$.

\section{Discussion}

\section{Diurnal activity budgets}

Activity budgets of grey rhebok are not well described by other authors. Beukes (1984) found that foraging was the dominant activity, taking up $56 \%$ of daylight hours.

Assuming foraging in this case meant being active, this was very similar to the results of the present study.

Activity budgets of mountain reedbuck are also not previously well described, with Irby (1981, 1982) only giving a break down of periods of activity and inactivity. Southern mountain reedbuck at Loskop Dam Nature Reserve, South Africa, showed an average diurnal activity frequency of $47 \%$ (Irby, 1981). Of this, feeding comprised $62 \%$ and, therefore, made up an average of $29 \%$ of the daily activity budget. The results from Chanler's mountain reedbuck in Kenya were very similar (Irby, 1982) and both were, therefore, similar to the results of the present study. Roberts \& Dunbar (1991) provide a break down of activity budgets into other behaviours including feeding, resting, standing, moving and other infrequent behaviour. Chanler's mountain reedbuck at Eburru Cliffs, Kenya, spent $39 \%$ of diurnal observations feeding (males and females were similar). There were no inter-sexual differences in time budgets across months for feeding, moving and standing, although females lay down more than males.

\section{Diurnal activity patterns}

The common trend in the diurnal activity patterns of grey rhebok and mountain reedbuck at Sterkfontein was that animals generally rested more in the middle of the day, and fed more in the early morning and late afternoon. The pattern was more accentuated in mountain reedbuck, which were especially active in late afternoon.

Esser (1973) found a similar pattern of increased foraging activity in the late afternoon in grey rhebok. Beukes (1984) indicated that the activity patterns of the male and females within a harem herd alternated, so that when the male was active, the females were not, and vice versa. This was suggested to result from the advantage conveyed by always having some animals vigilant. In contrast, the present study found that during most observation periods males and females were generally active or inactive at the same time. 
It was a common occurrence that once one animal within a herd lay down, the rest followed suit within a few minutes.

Beukes (1984) found that grey rhebok spent more time feeding in winter (June) than summer (December), although there was no seasonal influence on the overall activity budget. The feeding differences were thought to result from changes in the availability of young plant material and protein content caused by changes in rainfall. The present study found a similar increase in time spent feeding in winter compared with summer. At Sterkfontein many forbs lignified and died during winter (A. Taylor, pers. obs.), making food quality relatively poor compared with summer.

The activity patterns of mountain reedbuck in the present study were similar to those found by Irby $(1981,1982)$ at Loskop, and in the Rift Valley, Kenya, as well as by Roberts \& Dunbar (1991) at Eburru Cliffs. The two Kenyan studies were conducted on Chanler's mountain reedbuck, a subspecies of the southern mountain reedbuck found in South Africa. These studies found that mountain reedbuck had well-defined diurnal cycles of activity, with distinct resting periods around midday. The activity cycles of males and females were closely correlated, with temperature being an important determinant of activity. The diurnal cycles found by Irby $(1981,1982)$ and Roberts \& Dunbar (1991) were more extreme than was the case at Sterkfontein, with the earlier studies finding that mountain reedbuck became almost totally inactive in the middle of the day. One factor that could have been responsible for this difference was the temperature at midday. Maximum diurnal temperature at Eburru Cliffs was $35^{\circ} \mathrm{C}$ in summer (Roberts \& Dunbar, 1991), while at Loskop they were $32^{\circ} \mathrm{C}$ (Irby, 1981). Maximum diurnal temperature at Sterkfontein was only $25^{\circ} \mathrm{C}$ in summer, and this may have allowed animals to remain active occasionally at the warmest time of day.

Klein \& Fairall (1986) compared the foraging behaviour of a grazing antelope, the blesbok (Damaliscus dorcas), with that of a mixed feeder, the impala (Aepyceros melampus). They found that the grazer spent less time feeding and more time resting than the mixed feeder, and the reasons for this were thought to be associated with the formers efficiency as a bulk feeder, as well as the longer time required for digestion of its coarser diet. In the present study, the grazing mountain reedbuck were, therefore, expected to spend less time feeding and more time resting (ruminating) than the browsing grey rhebok. Although the mountain reedbuck spent a greater proportion of the day resting than the grey rhebok, this difference was not significant. The mountain reedbuck also spent more time ruminating than grey rhebok, but this was not tested statistically. 


\section{Nocturnal activity patterns}

Grey rhebok were active at night to a similar degree ( $57 \%$ mixed gender) as they were during the day (60\% males, $56 \%$ females). No previous studies have monitored activity at night, although Beukes (1984) suggested that they might be less active at night. Clearly this is not the case at Sterkfontein.

Mountain reedbuck were more active at night ( $72 \%$ mixed sex) compared with the day (43\% males, $46 \%$ females), although the number of observations was low. This agreed with Roberts \& Dunbar (1991), who found that Chanler's mountain reedbuck in Kenya were also active throughout the night, with periodic peaks and troughs in feeding and resting. Activity levels tended to be higher at night than during daylight, with less pronounced resting periods. Most southern African antelope species are active at night to some degree (Skinner \& Smithers, 1990), but in many cases the extent to which they are is not well studied.

\section{References}

BEUKES, P.C. (1984) Sommige aspekte van die ekologie van die vaalribbok (Pelea capreolus, Forster 1790) in die Bontebok Nasionale Park. Unpublished MSc Thesis, University of Stellenbosch, , 176 pp.

•

BeuKes, P.C. (1988) Diet of grey rhebok in the Bontebok National Park. S. Afr. J. Wildl. Res. 18, 11-21.

BREDENKAMP, G. \& van,Rooyen, N. (1996) Moist cool highveld grassland. In: Vegetation of South Africa, Lesotho and Swaziland (Eds A. B. LOW and A. G. REBELO). Dept Environmental Affairs and Tourism, .

DUNBAR, R.I.M. \& RoBERTS, S.C. (1992) Territory quality in mountain reedbuck (Redunca fulvorufula chanleri): distance to safety. Ethology 90, 134-142.

-

EsSER, J. (1973) Beitrage zur Biologie des afrikanischen Rhebockes (Pelea capreolus Forster 1790). DSc Thesis, Christian-Albrechts-Universitat, , 125 pp.

FERREIRA, N.A. (1983) The status, distribution and habitat requirements of the grey rhebok, Pelea capreolus (Forster 1790) in the Orange Free State. Unpublished MSc Thesis, University of Stellenbosch, , 204 pp. 
FERrEIRA, N.A. \& BigALKe, R.C. (1987) Food selection by grey rhebok in the Orange Free State. S. Afr. J. Wildl. Res. 17, 123-127.

IRBY, L.R. (1976) The ecology of mountain reedbuck in southern and eastern Africa. Unpublished PhD Thesis, Texas A\&M University, , 248 pp.

IRBY, L.R. (1979) Reproduction in mountain reedbuck (Redunca fulvorufula). Mammalia 43, 191-213.

IRBY, L.R. (1981) Mountain reedbuck activity patterns in the Loskop Dam Nature Reserve. S. Afr. J. Wildl. Res. 11, 115-120.

IRBY, L.R. (1982) Diurnal activity and habitat use patterns in a population of Chanler's mountain reedbuck in the Rift Valley of Kenya. Afr. J. Ecol. 20, 169-178.

-

KLEIN, D.R. \& FAIRALL, N. (1986) Comparative foraging behaviour and associated energetics of impala and blesbok. J. Appl. Ecol. 23, 489-502.

MARTin, P. \& BATESON, P. (1993) Measuring Behaviour: an Introductory Guide, 2nd edn. Cambridge University Press, , 222 pp.

-

MAtThEe, C.A. \& DAVIS, S.K. (2001) Molecular insights into the evolution of the family Bovidae: a nuclear DNA perspective. Molecular Biology and Evolution 18, 1220-1230.

RoBERTS, S.C. \& DunBAR, R.I.M. (1991) Climatic influences on the behavioural ecology of Chanler's mountain reedbuck in Kenya. Afr. J. Ecol. 29, 316-329.

-

Rowe-Rowe, D.T. (1983) Habitat preferences of five Drakensburg antelopes. S. Afr. J. Wildl. Res. 13, 1-8.

-

Rowe-Rowe, D.T. (1994) The Ungulates of Natal, 2nd edn. Natal Parks Board, , 35 pp.

Skinner, J.D. \& SMithers, R.H.N. (1990) The Mammals of the Southern African Subregion, 2nd edn. University of Pretoria, , $771 \mathrm{pp}$.

-

TAYLOR, W.A. (2004) Factors influencing productivity in sympatric populations of Mountain Reedbuck and Grey Rhebok in the Sterkfontein Dam Nature Reserve, South Africa. Unpublished PhD Thesis, University of Pretoria, , 195 pp. 
Fig 1 Activity budgets of (a) harem male grey rhebok; (b) female grey rhebok; (c) grey rhebok lambs at Sterkfontein

(a) Harem male grey rhebok

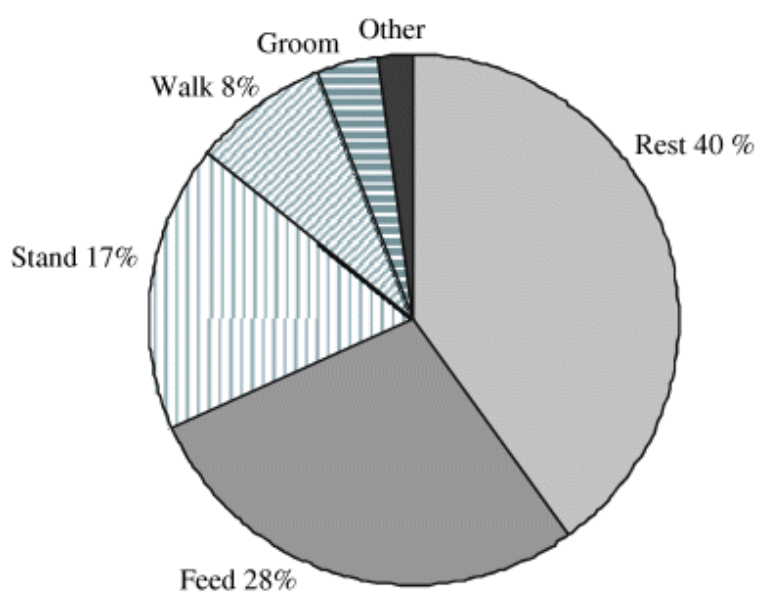

(b) Female grey rhebok

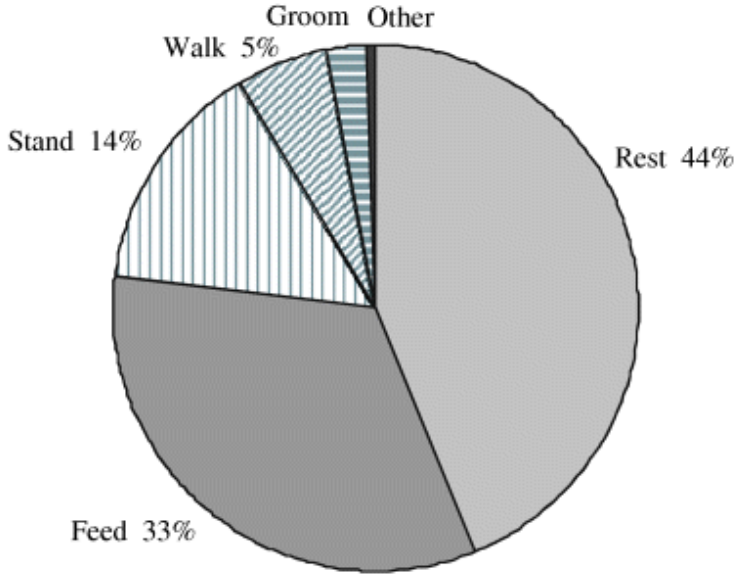

(c) Grey rhebok lambs

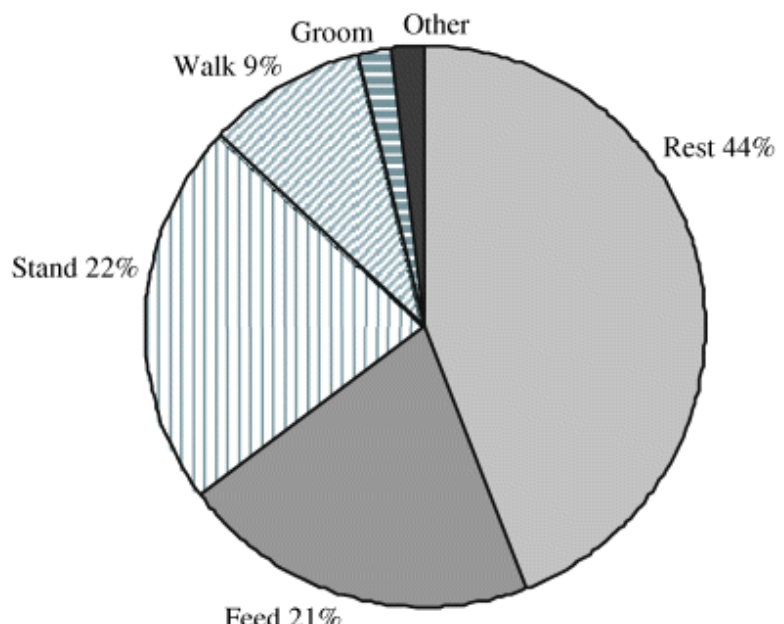


Fig 2 Activity budgets of (a) territorial male mountain reedbuck; (b) females mountain reedbuck at Sterkfontein

(a) Territorial male mountain reedbuck

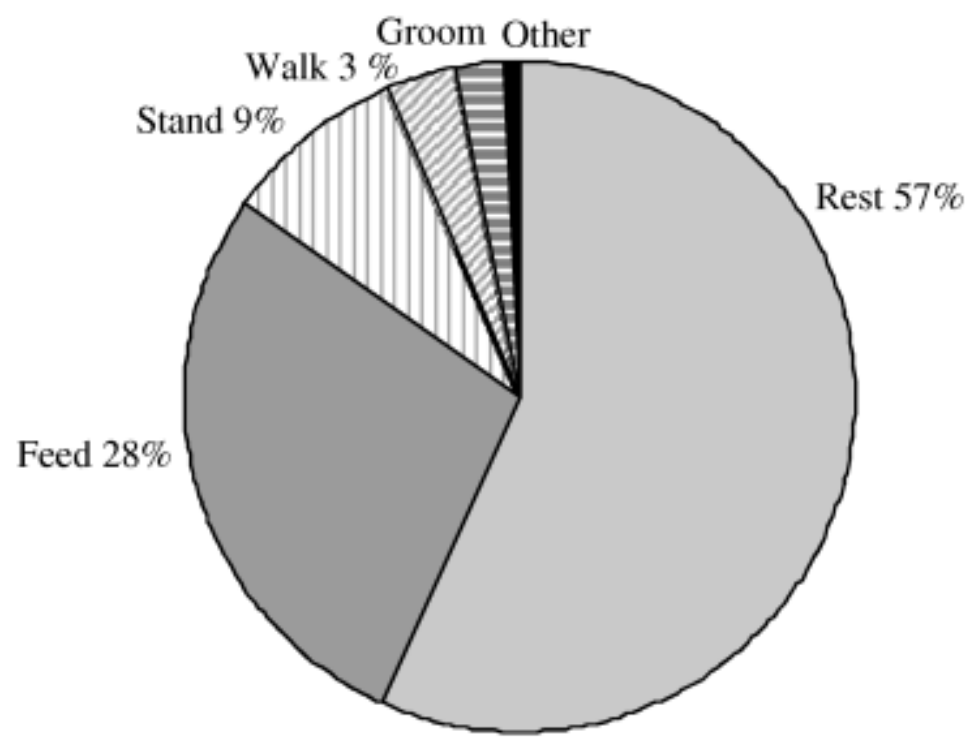

(b) Female mountain reedbuck

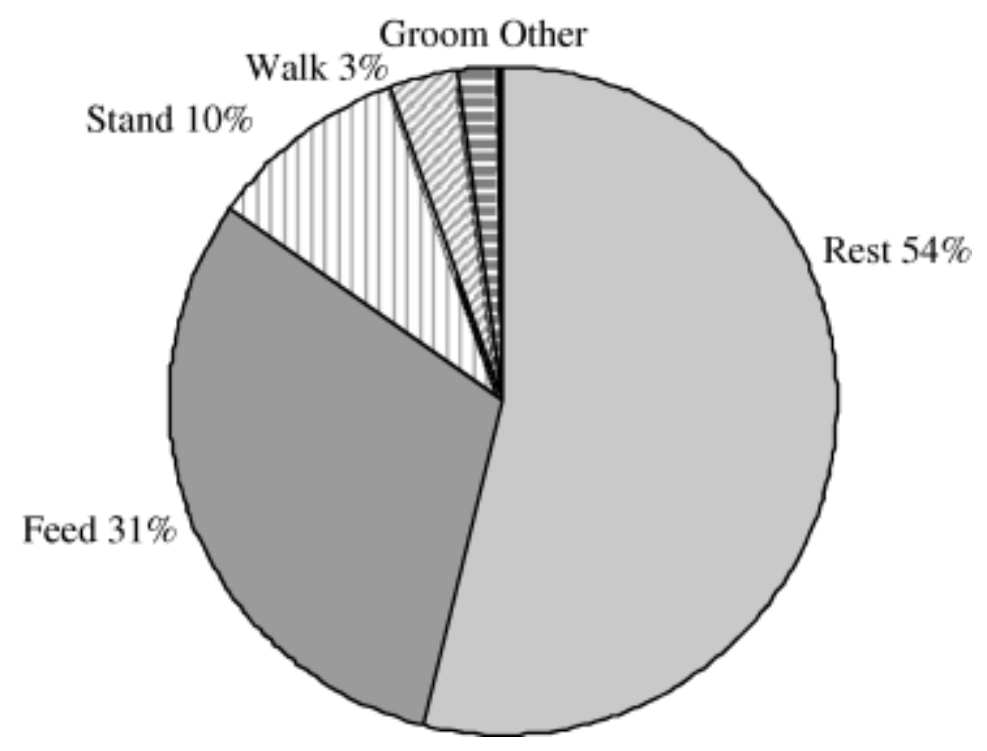


Fig 3 Activity patterns of grey rhebok and mountain reedbuck at Sterkfontein: (a) male grey rhebok summer, (b) male grey rhebok winter, (c) female grey rhebok summer, (d) female grey rhebok winter, (e) male mountain reedbuck summer, (f) male mountain reedbuck winter, (g) female mountain reedbuck summer, (h) female mountain reedbuck winter. $06 \mathrm{~h}=06.00-08.59$ hours; $09 \mathrm{~h}=09.00-11.59$ hours; $12 \mathrm{~h}=12.00-14.59$ hours; $15 \mathrm{~h}=15.00-17.59$ hours
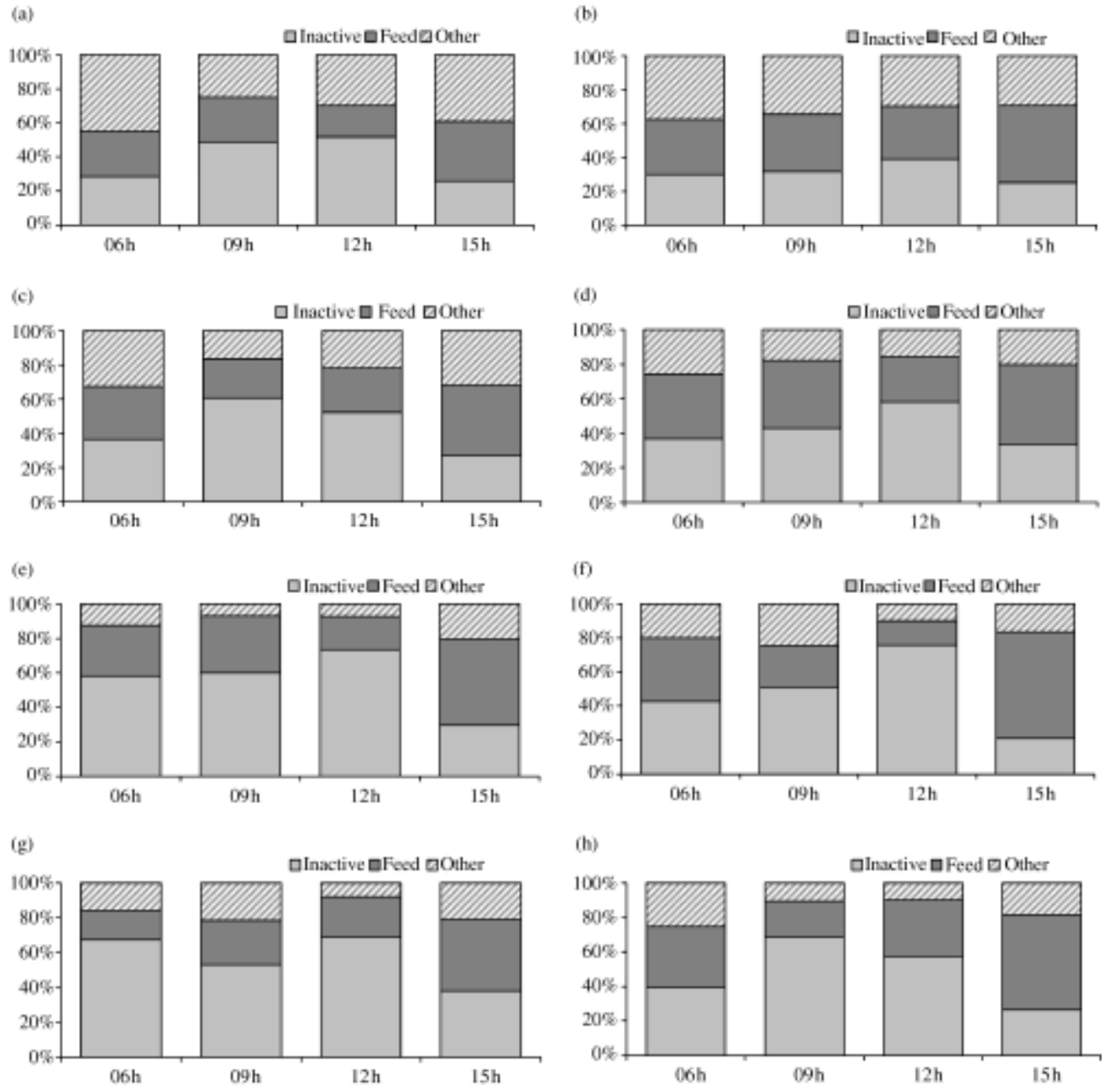